\title{
Autosomal dominant iridogoniodysgenesis with associated somatic anomalies: four-generation family with Rieger's syndrome
}

\author{
I. A. CHISHOLM AND A. E. CHUDLEY \\ From the Department of Ophthalmology and Division of Medical Genetrics, Department of Pediatrics, \\ University of Saskatchewan
}

SUMMARY A family extending over 4 generations showed iridogoniodysgenesis accompanied by somatic malformations inherited in an autosomal dominant fashion. Iridogoniodysgenesis was present in 10 members, of whom 5 had established glaucoma; 4 youthful members are likely to develop glaucoma. Somatic malformations were present in 5 members from the 3rd and 4th generations who did not manifest iridogoniodysgenesis. A possible polygenic basis is discusssed, though the variable expression of an autosomal dominant inheritance is still the more likely explanation.

The contribution of goniodysgenesis to the pathogenesis of hereditary juvenile glaucoma has been described. ${ }^{12}$ The term embraces a maldevelopment of the trabecular meshwork, hypoplasia of the anterior stromal layer of the iris, and anomaly of the peripheral cornea-Rieger's ocular malformation. For those patients in whom the iris hypoplasia is marked and corneal involvement absent iridogoniodysgenesis is the preferred descriptive term. ${ }^{3}$ Families with hereditary juvenile glaucoma are known in whom a dominantly inherited iridogoniodysgenesis is both prominent and a significant indicator of the accompanying glaucoma,${ }^{4-7}$ but in none have somatic malformations been reported. We report a family over 4 generations showing marked iris hypoplasia present from birth accompanied by glaucoma in early adulthood, associated with somatic malformations of an autosomal dominant inheritance.

\section{Materials and methods}

Access to the family was obtained via III $_{10}$ and siblings (Fig. 1). He had undergone bilateral thermal sclerostomy for the control of glaucoma at the age of 25 years and was seeking advice on behalf of his children. He was aware of a connection between iris colour and

Correspondence to Dr I. A. Chisholm, FRCS Ed, Department of Ophthalmology, College of Medicine, University of Saskatchewan. Saskatoon, Canada S7N OXO. blindness, as his grandfather, father, and an aunt who had similar dark brown irides to his were blind by their 40s. Two of his children had a similar iris colour.

Our assessment of the subjects entailed an ocular examination, general physical examination, removal of blood samples for chromosome studies, and photography. The ocular examination consisted of a recording of visual acuity and refraction if indicated, slit-lamp examination of the anterior segment, gonioscopy, measurement of anterior chamber depth and corneal diameter, observation of pupil shape and motility, and recording of the applanation intraocular pressure. Detailed examination of the visual field was also performed where indicated. A diagnosis of glaucoma was reached on finding raised intraocular pressure with cupping of the optic disc supplemented with the finding of classical nerve bundle defects in the field of vision.

\section{Results}

Twenty-eight surviving members of the family were assessed and data obtained (Fig. 1). Fourteen were male and 14 female, of whom $10(35 \cdot 7 \%)$, namely, 4 male and 6 female, had marked iris hypoplasia and a distinct facial resemblance (Fig. 2). I, though deceased possessed features compatible with the disorder, which were documented by history and examination 529 of photographs. 
Fig. 1 Pedigree. Note the autosomal dominant pattern of inheritance and wide variation in expression of the component manifestations.

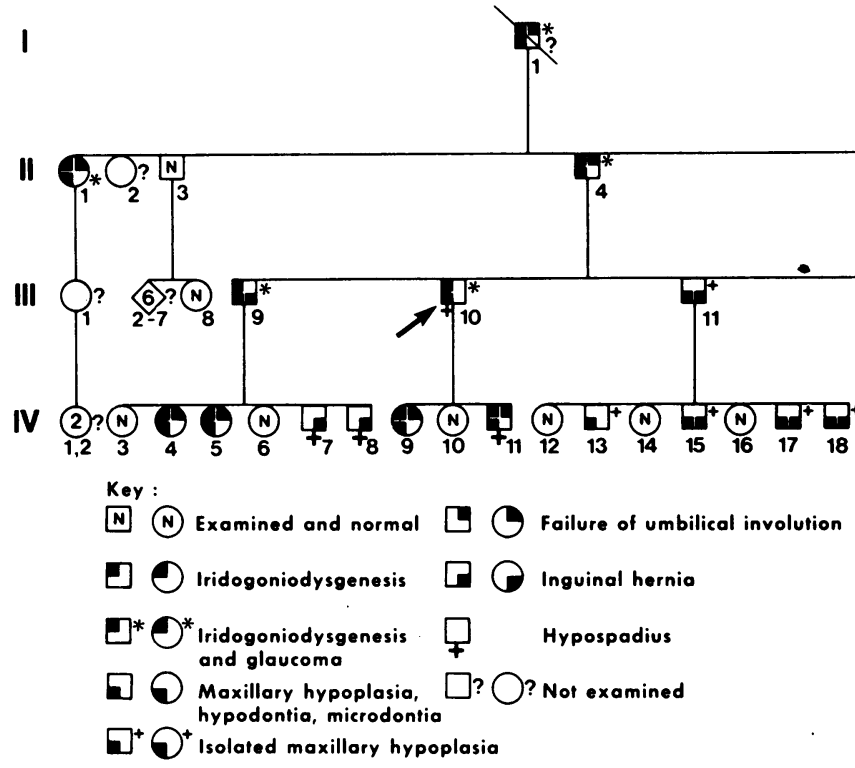

\section{OCULAR FINDINGS}

Glaucoma was found in 5 members, 2 female and 3 male, all of whom showed iris hypoplasia. Intraocular pressure control was achieved by medical means alone in 1 (III), repeated surgical procedures in 2 $\left(\mathrm{II}_{1}\right)$ and $\left(\mathrm{II}_{4}\right)$, and by a combination of surgery with continued medical therapy in 1 (III $\left.{ }_{10}\right)$. The glaucoma recently diagnosed in $\mathrm{IV}_{20}$ appears to be unresponsive
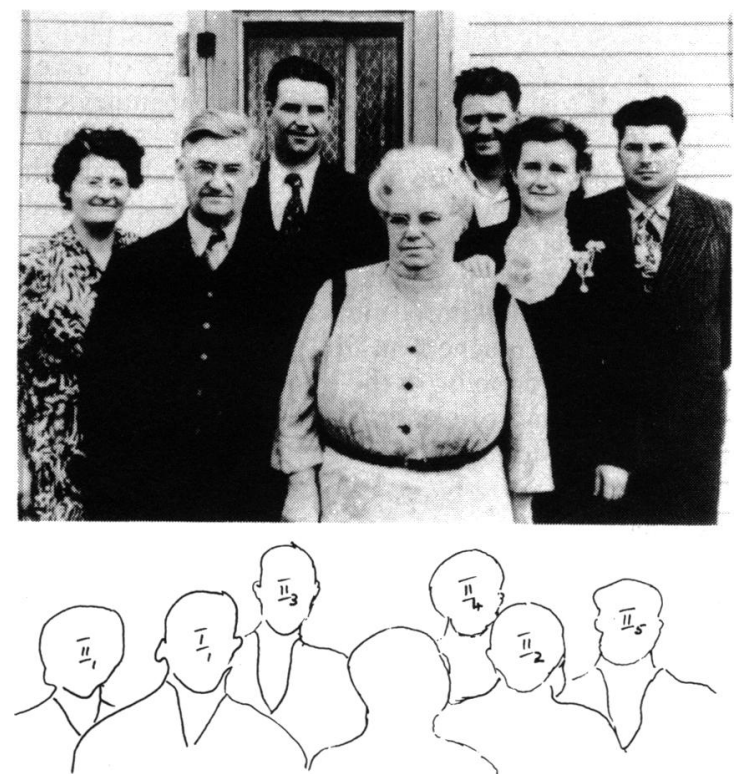

Fig. 2 Family group with key; note facial resemblance between $I_{1}, I I_{1}$, and $I I_{4}$. to medical therapy. Glaucoma was not diagnosed in $\mathrm{II}_{1}$ and $\mathrm{II}_{4}$ until they were in their 40 s, by which time visual loss was severe. Glaucoma was diagnosed in III, and III $_{10}$ when they were in their early 20 s and in $I_{20}$ at 18 years of age. None of the subjects who had normal iris structure show glaucoma. The sister of the propositus ( $\mathrm{III}_{12}$ ) is the only subject in her generation with iris hypoplasia who does not show glaucoma. Subjects $\mathrm{IV}_{4}, \mathrm{IV}_{5}, \mathrm{IV}_{9}$, and $\mathrm{IV}_{11}$ who have iris hypoplasia but not as yet glaucoma must be considered at high risk of developing the disease.

The iris hypoplasia found in 10 members of the family was bilateral, present from birth, and imparted a characteristic dark brown colour to the iris. Slitlamf examination revealed absence of the anterior leaf of the iris stroma (Figs. 3-6). The posterior leaf was gossamer thin, throwing into sharp prominence the pale band of the sphincter muscle and numerous radial strands. Retroillumination of the iris revealed no dehiscences of the posterior epithelium.

Minor developmental changes were identified in the lens of eyes with iris hypoplasia. These consisted of epicapsular stars on the anterior lens capsule, and small white flake opacities in the anterior lens suture. Eyes with normal iris structure did not show these changes.

The eyes with iris hypoplasia had normal sized corneas and no evidence of posterior embryrotoxon (Figs. 3-6). The anterior chamber appeared deep, but the depth centrally as measured by the HaagStreit pachometer in the affected subjects from the $3 \mathrm{rd}$ and 4th generation was $3 \cdot 4, \mathrm{SD} 0.8 \mathrm{~mm}$ (normal for 15-35-year group is $3 \cdot 60$, SD $0.039 \mathrm{~mm}^{8}$ ). 


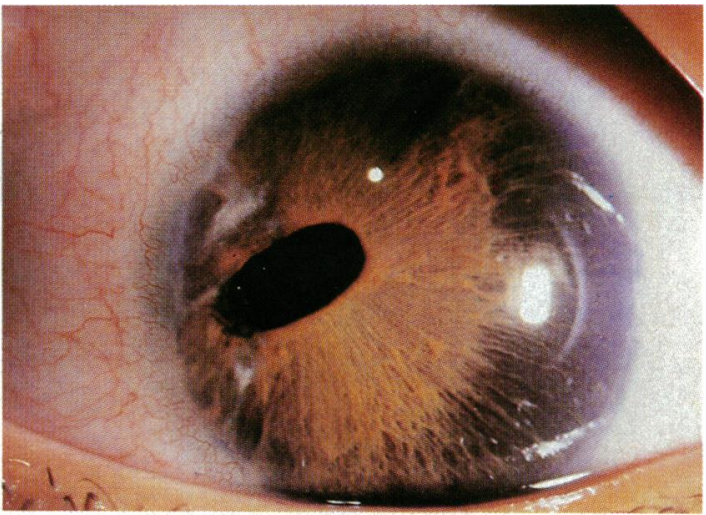

Fig. 3 Typical Rieger's ocular malformation (for comparison).

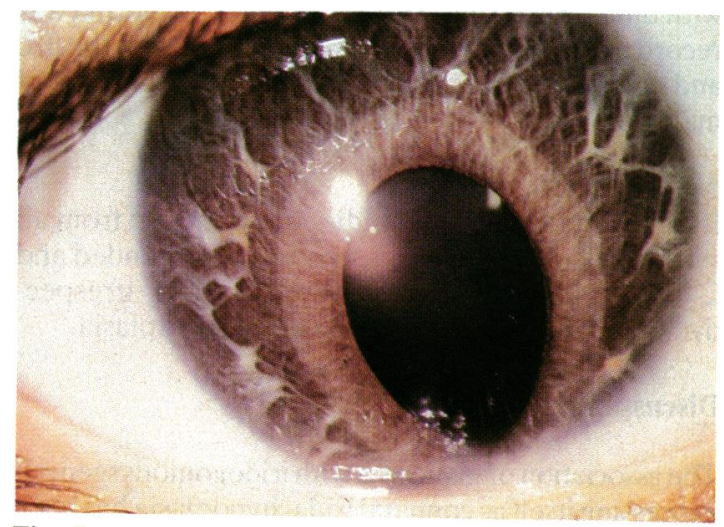

Fig. 5

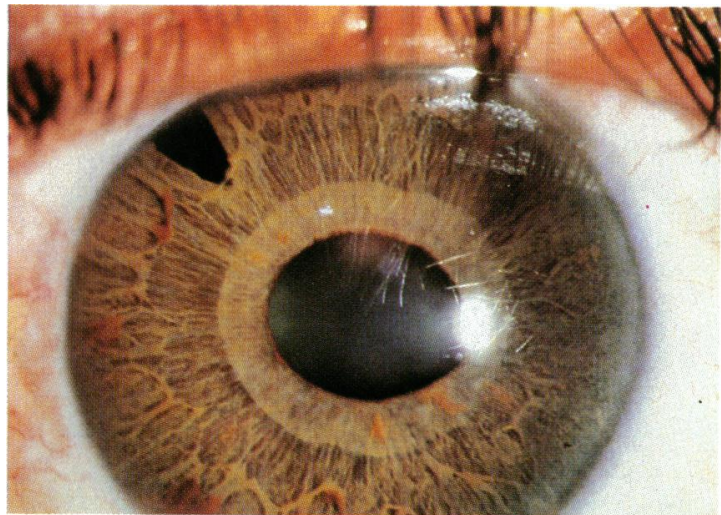

Fig. 4 Right eye $I I I_{10}$ showing peripheral iridectomy, oval pupil, prominent sphincter band, iris hypoplasia.

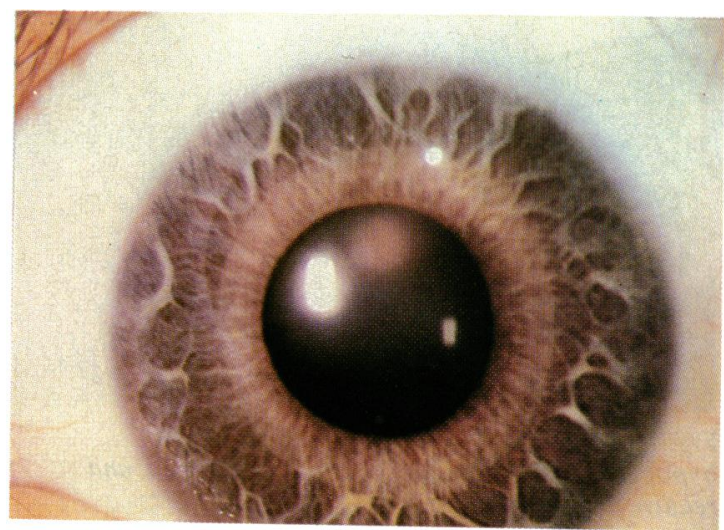

Fig. 6

Figs. 5 and 6 Right and left eye $V_{20}$ showing iris hypoplasia and prominent sphincter band; right showing broad anterior synechium below with corneal opacities.

Gonioscopy showed an anterior origin of the iris from approximately the scleral spur with a network of fine strands passing forwards towards Schwalbe's line apparently internal to the trabeculum. The angles were wide.

The pupil of eyes with iris hypoplasia was solitary, central, and active to light stimulation. In 3 subjects the eyes were myopic and the pupils in those eyes tended to be horizontally oval and to show pupillotonia (III $10, \mathrm{IV}_{4}$ and $\mathrm{IV}_{20}$ ) (Figs. 3-6).

Of the 20 eyes with iris hypoplasia only one differed from the above. The right eye of I. $V_{20}$ showed downward displacement of the pupil because of a broad anterior adhesion of the iris to the posterior periphery of the cornea, obliterating the angle of the anterior chamber in that area (Figs. 3-6). The remainder of the angle in this eye was as described above. Whitish spots were present in the deep layer of the corneal stroma. This eye was the only one in the series which approximated to the description of Rieger's ocular malformation.

\section{SOMATIC MANIFESTATIONS}

Mention has already been made of the facial resemblance of subjects with iris hypoplasia. This was due to maxillary hypoplasia and its association with a short philtrum and the protruding lower lip of mild prognathism (Fig. 7). In this family maxillary hypoplasia was accompanied by dental anomalies (microdontia, hypodontia, and cone-shaped teeth) (Fig. 8) and was to be found in all the subjects who had iris hypoplasia and in some (III ${ }_{11}$ and his siblings) who did not. In all, 15 subjects showed maxillary hypoplasia.

By history or observation the failure of involution of the umbilicus was recorded in 8 subjects ( 2 male, 6 female) (Fig. 9). In the majority, this had been treated surgically in the neonatal period due to its confusion 


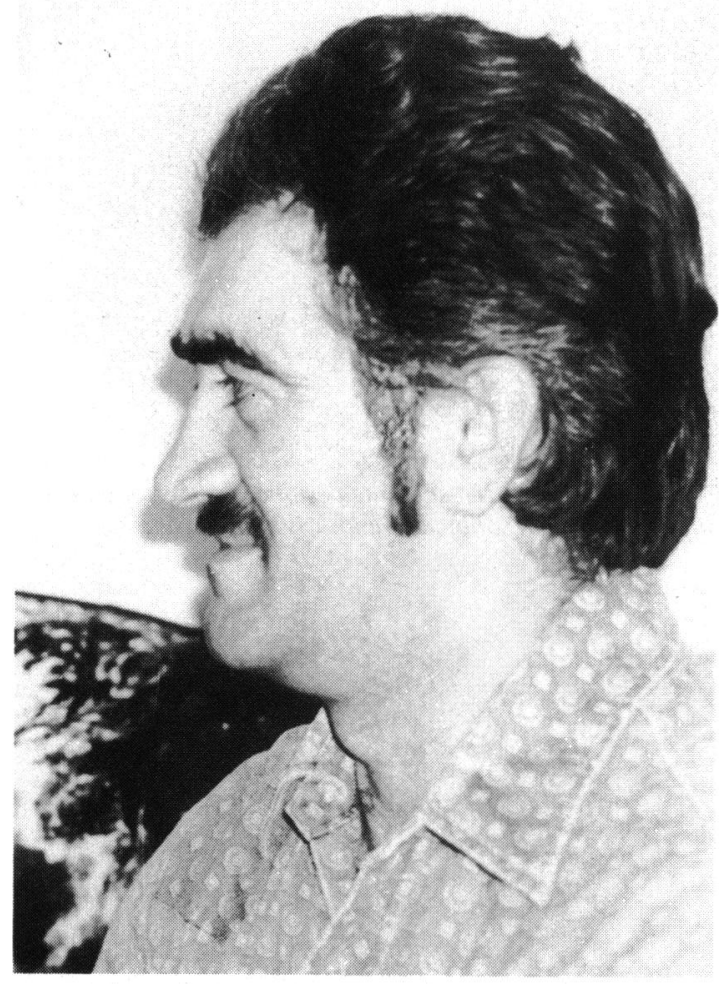

Fig. 7 Profile view of III $_{10}$ illustrating maxillary hypoplasia, short philtrum, protruding lower lip, and relative prognathism.

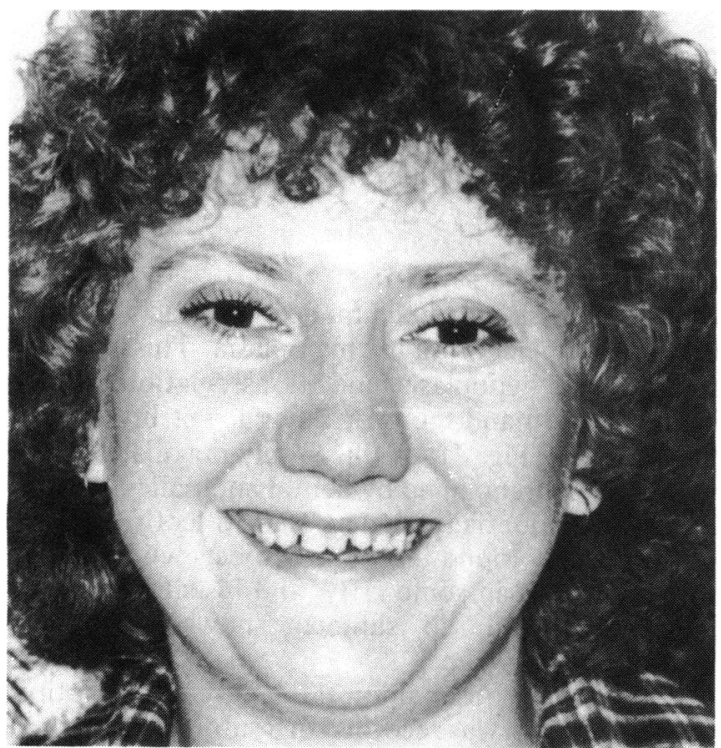

Fig. 8 Facial view $\mathrm{IV}_{4}$; illustrating typical dark eyes, facial and dental amomalies.

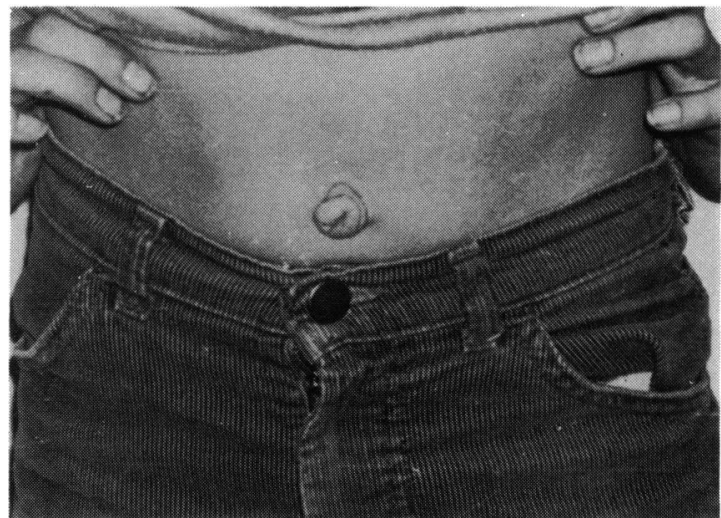

Fig. $9 \quad V_{11}$ showing failure of umbilical involution.

with umbilical hernia. Surgery for inguinal hernia was recorded in 8 subjects ( 7 male, 1 female) from the 3 rd and 4 th generations. Hypospadias was found in 4 males.

CYTOGENETIC STUDIES

Blood for chromosomal studies was obtained from all surviving family members. Analysis of G-banded and C-banded karyotypes was entirely normal, irrespective of the presence or absence of iris hypoplasia.

\section{Discussion}

The association of glaucoma with iridogoniodysgenesis expressing itself as connatal iridal hypoplasia has been demonstrated in several family studies. ${ }^{24} 7$ None, however, describe somatic malformations; Alkemade ${ }^{9}$ used this to stress that the malformation expressing itself as connatal iridal hypoplasia was confined to the eye. Typically such eyes had chocolate brown irides with little visible stromal structure, did not alter from birth, and were accompanied by an intractable form of glaucoma in early adulthood. Hambresen and Schepens ${ }^{5}$ recorded that in affected families where the prognostic significance of the iris colour was known the eyes of newborn infants were scrutinised for this tell-tale sign.

The affected eyes in this family conform in all respects to the earlier reports with one exceptionthe right eye of $I V_{20}$, whose appearance would be in keeping with Rieger's ocular malformation.

A combination of the Rieger ocular malformation, one of the anterior chamber cleavage syndromes, ${ }^{10}$ with facial and dental abnormalities, traditionally constituted the Rieger syndrome. ${ }^{11} 12$ This syndrome, inherited in an autosomal dominant manner with complete penetrance, showed a wide variation in the expression of its features. ${ }^{1314}$ Approximately $25 \%$ of reported cases may be considered to be sporadic. 
Table 1 Summary of ocular features

\begin{tabular}{lllllll}
\hline Age & Glaucoma & $\begin{array}{l}\text { Open angle, } \\
\text { anterior } \\
\text { origin of iris }\end{array}$ & $\begin{array}{l}\text { Myopia, } \\
\text { dyscoria, } \\
\text { pupillotonia }\end{array}$ & $\begin{array}{l}\text { Develop- } \\
\text { mental } \\
\text { changes } \\
\text { in lens }\end{array}$ \\
\hline II $_{1}$ & F & 80 & + & Anterior segments distorted by \\
II $_{4}$ & M & 71 & + & glaucoma and cataract surgery \\
III $_{9}$ & M & 48 & + & + & - & + \\
III $_{10}$ & M & 45 & + & + & + & + \\
III $_{12}$ & F & 40 & - & + & - & + \\
IV $_{4}$ & F & 23 & - & + & + & - \\
IV $_{5}$ & F & 20 & - & + & - & - \\
IV $_{9}$ & F & 13 & - & + & - & + \\
IV $_{11}$ & M & 10 & - & + & - & + \\
IV $_{20}$ & F & 18 & + & + & + & + \\
\hline+ & & & & + & & + \\
I $_{-}$ & Feature present. & & & &
\end{tabular}

This may be an overestimate, since many of the other family members at risk were not recorded, and many of the reports failed to discuss the extraocular manifestations.

Recent reviews of the Rieger syndrome adequately list the extraocular, extradental, and extrafacial anomalies of the reported families. ${ }^{1516}$ The somatic abnormalities most commonly seen in reported families were also found in the family reported here. Of particular note were the failure of involution of the umbilicus in most of the individuals who had the eye abnormalities ( 9 out of 11), inguinal hernias seen in 8 of 28 individuals at risk, and hypospadias also seen in 4 of the affected males. Inguinal hernias and hypospadius in the Rieger syndrome have been reported in a number of families ${ }^{917}$ and appear to be a frequent associated feature.

The family in this report appears to be unique in that all of the affected members with eye manifestations have iridogoniodysgenesis in which the prominent Schwalbe's line is absent but iris strands to Schwalbe's line and iris hypoplasia are present. However, both goniodysgenesis and iridogoniodysgenesis, which are part of the spectrum of mesenchymal dysgenesis of the anterior ocular segment, may share a common aetiology, and this finding may just reflect the highly variable nature of this autosomal dominant syndrome.

One section of the present family offers some confusion and difficulty with genetic counselling. III $_{11}$ has no eye anomalies but manifests some of the associated somatic features such as a short philtrum, maxillary hypoplasia, an unknown reason for removal of all his teeth (he claims he had infected gums-no dental records available), and inguinal hernias repaired.

None of his children had iridogoniodysgenesis. All 4 of his sons have maxillary hypoplasia without teeth anomalies, short philtrum, and 3 of the 4 had inguinal hernias. We were not certain whether this man and his sons carried the culpable gene. Nevertheless, we discussed this dilemma with the family and advised them that possibly they were mildly affected, and that the grandchildren should be followed up closely after birth and evidence sought for the potential eye involvement and extraocular somatic complications.

The mode of inheritance in this family, as with previously reported families, would be consistent with an autosomal dominant pattern. The variable expression in autosomal dominant conditions is notorious. An alternative explanation for this degree of variability in the family could be that we were not dealing with a single gene abnormality but a polygenic trait, with the altered genes being closely linked and each coding for a specific anomaly. Assuming a single gene trait, using III $_{11}$ and his children as an example, we would expect to see iridogoniodysgenesis in at least some of his children. The fact that none have the eye anomaly, but 4 of the 7 children have some associated features of the syndrome, would make the polygenic theory plausible. However, this is a less satisfactory explanation than the autosomal dominant hypothesis. It would be important for others to report similar findings in other families to help us gain further insight into the genetics of this disorder.

A number of reports have suggested that the Rieger anomaly may be seen in other malformation syndromes associated with chromosomal abnormalities. ${ }^{1821}$ Chromosome studies in the family of this report were all normal and no polymorphisms were found. It is likely the pericentric inversion of chromosome 6 that was found in a girl and her father, both with the Rieger syndrome,$^{20}$ was fortuitous and not representative of a chromosomal marker for the altered gene.

Since the Rieger syndrome is a systemic heritable disorder, recognition of the ocular malformation should alert the ophthalmologist to examine the firstdegree relatives of the presenting patient and also institute a thorough search for evidence of any of the possible extraocular malformations in affected individuals. Therefore it would seem prudent to refer individuals with the Rieger anomaly to geneticists or other specialists who can carry out the appropriate investigations and provide genetic counselling.

We record our thanks to the Clinical Teaching and Research fund, College of Medicine, University of Saskatchewan, for financial assistance, to $M$. Handford for the colour photographs, and to M. Kidd for secretarial assistance.

\section{References}

1 Cromble AL, Cullen JF. Hereditary glaucoma: occurrence in five generations of an Edinburgh family. Br J Ophthalmol 1964; 48: 143-7.

2 Jerndal T. Goniodysgenesis and hereditary juvenile glaucoma. Acta Ophthalmol (Kbh) 1970; suppl 107. 
3 Waring GO, Rodriques MM, Laibson PR. Anterior chamber cleavage syndrome. A stepladder classification. Surv Ophthalmol 1975; 20: 3-27.

4 Berg F. Erbliches jugendliches Glaukom. Acta Ophthalmol (Kbh) 1932; 10: 568-87.

5 Hambresen L, Schepens C. Glaukome familiale. Bull Soc Ophtalmol Fr 1932; 59: 219-23.

6 François J, Deweer JP, vanden Berghe J. Chronic simple glaucoma with dominent heredity. Bull Soc Belge Ophtalmol 1950; 96: 665-83.

7 Weatherill JR, Hart CT. Familial hypoplasia of the iris stroma associated with glaucoma. Br J Ophthalmol 1969; 53: 433-8.

8 Weekers R, Grieten J, Lavergne G. Study of the dimensions of the human anterior chamber. Ophthalmologica 1961; 142: 650-62.

9 Alkemade PPH. Dysgenesis mesodermalis of the iris and the cornea. Assen; Van Gorcum, 1969.

10 Reese $A B$, Ellsworth RM. The anterior chamber cleavage syndrome. Arch Ophthalmol 1966; 75: 307-18.

11 Rieger H. Beitrage zur Kenntnis seltner Missbildungen der Iris; Membrana iridopupillaris persistens. Albrecht von Graefes Arch Klin Ophthalmol 1934; 131: 523-30.

12 Rieger H. Beitrage zur Kenntnis seltner Missbildungen der Iris; ueber Hypoplasie des Irisvorderblattes mit Verlatgerung und
Entrundung der Pupillie. Albrecht von Graefes Arch Klin Ophthalmol 1935; 133: 602-35.

13 Jorgenson RJ, Voder FE, Levin LS. The Reiger syndrome. J Med Genet 1979; 16: 236-7.

14 Cross $\mathrm{HE}$, Penetrance and variability and anterior chamber malformations. Birth Defects 1979; 15: 131-44.

15 Jorgenson RJ, Levin LS, Cross HE, Yoder F, Kelly TE. The Rieger syndrome. Am J Med Genet 1978; 2: 307-18.

16 Fitch N, Kaback $M$. The Axenfeld syndrome and the Rieger syndrome. J Med Genet 1978; 15: 30-4.

17 Ferngold M, Shiere F, Fogels H, Donaldson D. The Rieger syndrome. Pediatrics 1969; 44: 564-9.

18 Tabbara KF, Khour FP, DerKaloustian VM. Rieger's syndrome with chromosomal anomaly. Can J Ophthalmol 1973; 8: 488-91.

19 Wilcos LM, Bercovitch L, Howard RO. Ophthalmic features of chromosome deletion 4p-(Wolf-Hirschhorn syndrome). Am J Ophthalmol 1978; 86: 834-9.

20 Heinemann MH, Breg R, Cotbier E. Rieger's syndrome with pericentric inversion of chromosome 6. Br J Ophthalmol 1979; 63: 40-4.

21 Akazawak Yamane S, Shiota H, Naito E. A case of retinoblastoma associated with Rieger's anomally and $13 q$ deletion. Jpn $J$ Ophthalmol 1981; 25: 321-5. 